\title{
Oxidative stress specifically downregulates survivin to promote breast tumour formation
}

\author{
S Pervin *,1,2,4 L Tran $^{2}$, R Urman ${ }^{2}, \mathrm{M}$ Braga ${ }^{1}, \mathrm{M}$ Parveen ${ }^{1}, \mathrm{~S}$ A Li ${ }^{3}, \mathrm{G}$ Chaudhuri ${ }^{2,4,5}$ and R Singh ${ }^{1,2,4}$ \\ ${ }^{1}$ Department of Internal Medicine, Charles Drew University of Medicine and Science, Los Angeles, CA 90059, USA; ${ }^{2}$ Department of \\ Obstetrics and Gynecology, Los Angeles, CA 90095, USA; ${ }^{3}$ Hormonal Oncogenesis Laboratory, University of Kansas Cancer \\ Center, Kansas, KA 66160, USA; ${ }^{4}$ Jonsson Comprehensive Cancer Center, Los Angeles, CA 90095, USA and ${ }^{5}$ Department of \\ Molecular and Medical Pharmacology, David Geffen School of Medicine at UCLA, Los Angeles, CA 90095, USA
}

Background: Breast cancer, a heterogeneous disease has been broadly classified into oestrogen receptor positive $(E R+)$ or oestrogen receptor negative (ER -) tumour types. Each of these tumours is dependent on specific signalling pathways for their progression. While high levels of survivin, an anti-apoptotic protein, increases aggressive behaviour in ER - breast tumours, oxidative stress (OS) promotes the progression of ER + breast tumours. Mechanisms and molecular targets by which OS promotes tumourigenesis remain poorly understood.

Results: DETA-NONOate, a nitric oxide (NO)-donor induces OS in breast cancer cell lines by early re-localisation and downregulation of cellular survivin. Using in vivo models of HMLE ${ }^{H R A S}$ xenografts and E2-induced breast tumours in $\mathrm{ACl}$ rats, we demonstrate that high OS downregulates survivin during initiation of tumourigenesis. Overexpression of survivin in HMLE ${ }^{H R A S}$ cells led to a significant delay in tumour initiation and tumour volume in nude mice. This inverse relationship between survivin and OS was also observed in ER + human breast tumours. We also demonstrate an upregulation of NADPH oxidase-1 (NOX1) and its activating protein p67, which are novel markers of OS in E2-induced tumours in $\mathrm{ACl}$ rats and as well as in ER+ human breast tumours.

Conclusion: Our data, therefore, suggest that downregulation of survivin could be an important early event by which OS initiates breast tumour formation.

Breast cancer is a complex disease that contains many heterogeneous cell types (Polyak et al, 2011). Molecular profiling has categorised five types of breast cancer, each of which contain many heterogeneous cells that cross-talk with each other and with their microenvironment through various signalling pathways (Korkaya et al, 2011; Perou et al, 2011). Despite the heterogeneity in every aspect of the disease, it is becoming evident that both oestrogen receptor positive $(E R+)$ and $E R$ - breast tumours are dependent on specific signalling pathways that play vital roles in the progression of these tumours. Survivin, a unique member of inhibitor of apoptosis (IAP) gene family is selectively overexpressed in malignant tissues, particularly in aggressive triplenegative human breast (TNHB) tumours (Muchmore et al, 2000; Youssef et al, 2008). In addition to inhibiting apoptosis, survivin increases survival and enhances angiogenesis, all of which promotes aggressive tumour behaviour and shortened disease-free survival (Li et al, 2006; Oliveras et al, 2011). Survivin expression in primary tumours and circulating breast cancer cells provide valuable information for predicting metastasis and recurrence of breast cancer (Yie et al, 2006; Adamkov et al, 2010). Since survivin has a crucial role in drug resistance, it has been essential to downregulate it to sensitise TNHB tumour cells to various therapeutic agents (Jha et al, 2012).

While increased survivin expression is a key feature of TNHB tumours, high oxidative stress (OS) is predominantly a characteristic of ER + breast tumours, which comprises $70 \%$ of all breast cancers (Quong et al, 2002; Mobley et al, 2004). Oxidative stress as assessed by 8-hydroxy deoxyguanosine (DNA damage) or 4-hydroxy-2-nonenal (lipid peroxidation) has been reported to be high in ER + human breast tumours (Karihtala et al, 2011). Mitochondria and NADPH oxidases can induce OS by producing reactive oxygen species (ROS) such as superoxide, hydrogen

*Correspondence: Dr S Pervin; E-mail: spervin@mednet.ucla.edu

Revised 7 January 2013; accepted 8 January 2013; published online 12 February 2013

(C) 2013 Cancer Research UK. All rights reserved 0007 - 0920/13 
peroxide and peroxynitrite that increase lipid peroxidation and DNA damage (Poyton et al, 2009; Coso et al, 2012). NOX1, an NADPH oxidase, which is known to increase ROS is overexpressed in $80 \%$ of all human breast tumours (Desouki et al, 2005). In addition, reduced activity of antioxidant enzymes like glutathione peroxidase (GPX) and superoxide dismutase (SOD) in ER + breast tumours are among other mechanisms that increase OS (Tsai et al, 2011; Panis et al, 2012). In ACI rat model of oestrogen-induced breast tumours, OS has been found to play an important role in tumour formation, which was attenuated by treatment with antioxidants like vitamin c, butylated hydroxyanisole and $\alpha$-naphthoflavone (Mense et al, 2009; Singh et al, 2012). In epidemiological studies, dietary anti-oxidants have been found to interact with endogenous sources of pro- and anti-oxidants to impact breast cancer risk in women (Sarhar et al, 2008; Li et al, 2009). However, OS-dependent mechanisms in specific cell types that promote initiation of tumours remain poorly understood.

We have previously reported that nitric oxide (NO)-induced OS upregulates an early stress-response gene MKP-1, that promoted mitochondria-mediated apoptosis in human breast cancer cell lines (Pervin et al, 2003a). We demonstrate using various in vitro and in vivo models that high OS suppresses survivin expression. We also show that high OS increased early re-localisation and decline of cytosolic survivin that preceded induction of MKP-1 in human breast cancer cell lines. Furthermore, overexpression of full-length human survivin in $\mathrm{HMLE}^{\mathrm{H}-\mathrm{RAS}}$ cells reduced tumour volume in nude mice. Therefore, based on our findings, we conclude that OS-mediated suppression of survivin in human breast tumours may be an important event in tumour initiation.

\section{MATERIALS AND METHODS}

Materials. Culture media, bovine serum and antibiotics were purchased from Gibco BRL (Gaithersburg, MD, USA). Human Insulin solution (\#19275) were purchased from Sigma (St Louis, MO, USA). The following primary antibodies were purchased from Santa Cruz Biotechnology (Santa Cruz, CA, USA) and used at 1:1000 dilutions or otherwise indicated: anti-human survivin (FL142, rabbit polyclonal), anti-human MKP-1 (sc-370, rabbit polyclonal), anti-human $\beta$-Actin (SC-81178, mouse monoclonal) anti-human NOX1 (SC-25545, rabbit polyclonal), anti-human NOX4 ( SC-21860, goat polyclonal), anti-human pp38MAPK (SC7973, mouse monoclonal), anti-human p38 MAPK (SC-7972, mouse monoclonal), anti-human p67 (SC-7663, goat polyclonal), anti-human p47 (SC-7660, goat polyclonal) and secondary peroxidase-conjugated anti-goat antibody (SC-2020). Peroxidaseconjugated anti-mouse (\#7076S) or anti-rabbit (\#7074S) secondary antibodies were purchased from Cell Signaling Technology, Inc. (Danvers, MA, USA). DETA-NONOate (\#82120) was purchased from Cayman Chemicals (Ann Arbor, MI, USA).

Cell lines. Human breast cancer cell lines MDA-MB-231, MDAMB-468 and MCF-7 were obtained from American Type Culture Collection (Manassas, VA, USA). Human mammary epithelial cells overexpressing $\mathrm{HMLE}^{\mathrm{H}-\mathrm{RAS}}$ (HRAS) were obtained from Dr Robert Weinberg (Whitehead Institute at MIT, Cambridge, MA, USA). These cells were cultured as described before (Pervin et al, 2003 b, 2008). For experimental purposes, cells were grown in $5 \%$ FBS, allowed to seed overnight and treated with drugs for various time periods.

Ethical statements. Tumour samples from $\mathrm{TN}\left(\mathrm{ER}^{-}, \mathrm{PR}^{-}\right.$, Her2 ${ }^{-}$) and $\mathrm{ER}^{+}$tumour patients were obtained from the following sources: (a) Cooperative Human Tissue Network (CHTN) (http://chtn.nci.nih.gov) (tumour samples were collected using NCI funded resource under OHRP guidelines and waiver of consent (45CFR46.101b) for anonymised samples; (b) National
Disease Research Interchange (NDRI) (http://ndriresourse.org) (approved biomedical research and Institutional Review Board (IRB) protocols from breast tumour patients after obtaining written consent) and (c) breast tumour and tissue repository at University of California, Los Angeles (UCLA) (approved biomedical research and IRB protocols from consented breast tumour patients). The research protocol was approved by the Charles Drew University IRB. This study was carried out in strict accordance with the recommendation in the Guide for the Care and Use of Laboratory Animals of the National Institute of Health. The protocol was approved by the Institutional Animal Care and Use Committee (IACUC) on the Ethics of Animal Experiments of the Charles Drew University of Medicine and Science. All surgery was performed under isoflurane anaesthesia, and all efforts were made to minimise suffering.

Microarray analysis. Total RNA was extracted from control and 16-h DETA-NONOate-treated cells using RNeasy kit (Qiagen, Valencia, CA, USA), according to the manufacturer's instructions. Reverse-transcription and hybridisation was performed essentially as described previously using Affymetrix U95A v2 chips (Santa Clara, CA, USA). Data analysis was performed in the Microarray Suite 5 and Data Mining Tool, v3 (Affymetrix).

Immunohistochemistry. Immunohistochemistry was performed as described previously (Singh et al, 2009). Briefly, tumour sections $(5-6 \mu \mathrm{m})$ were deparaffinised in xylene and rehydrated in water. Antigen retrieval was performed with target retrieval solution for 20-30 min. Non-specific staining was blocked with normal serum and incubated overnight at $4{ }^{\circ} \mathrm{C}$ with primary antibodies. This was followed by reaction with biotinylated anti-rabbit IgG (Vector Laboratories, Burlingame, CA, USA) for $30 \mathrm{~min}$, followed by treatment with the Avidin:Biotinylated enzyme complex (ABC complex) (1:100; Vector Laboratories, Burlingame, CA, USA) and $3,3^{\prime}$ diaminobenzidine (DAB). In some sets, the sections were counterstained with haematoxylin. Negative controls omitted the primary antibodies or replaced them with IgG isotype at the same concentration. All slides were dehydrated and mounted with permount. Tissue staining was quantified by quantitative image analysis (QIA) using the ImagePro 4.01 program (Media Cybernetics, Silver Spring, MD, USA) coupled to an Olympus BHS microscope equipped with a Spot RT colour digital camera (Diagnostic Instruments Inc., Sterling Heights, MI, USA).

Immunofluorescence. MDA-MB-468 cells were grown in chamber slides, fixed in $4 \%$ paraformaldehyde and immunofluorescence analysis was performed using anti-survivin antibody. Cells were further incubated with 1:200 dilution of secondary antibody conjugated with Texas-red and mounted in Prolong anti-fade solution (Molecular Probes, Eugene, OR, USA) as described previously (Singh et al, 2006; Braga et al, 2012).

Immunoblot. Immunoblot analysis was performed as described previously (Pervin et al, 2001, 2008). Briefly, lysates $(30 \mu \mathrm{g})$ were resolved electrophoretically on $4-15 \%$ gradient SDSpolyacrylamide gel and electro transferred to a polyvinylidine difluoride (PVDF) membrane, using a tank blot procedure (BioRad, Mini Protean II, Hercules, CA, USA). The membranes were incubated with survivin antibody (1:200), MKP-1 antibody (1:3000), NOX1 antibody (1:1000) and NOX4 (1:1000) for $2 \mathrm{~h}$ at room temperature followed by subsequent incubation with 1:1000 dilutions of respective secondary antibodies linked to horseradish peroxidase (GE Healthcare, Piscataway, NJ, USA) for $1 \mathrm{~h}$. Immunoreactive bands were visualised by the enhanced chemiluminescence (ECL) detection system (GE Healthcare).

Semi-quantitative RT-PCR. RT-PCR was performed as described previously (Pervin et al, 2003a). Total RNA from DETA-NONOate-treated cells was reverse transcribed, and 
the resulting cDNA was amplified as described previously with the following primer sets (Life Technologies Inc., Grand Island, NY, USA): Survivin sense, $5^{\prime}$-GCATGGGTGCCCCGACGTTG- ${ }^{\prime}$ ), and antisense, 5'-GCTCCGGCCAGAGGCCTCAA-3'; and glyceraldehyde-3-phosphate dehydrogenase (GAPDH) sense, 5'-GTGAAGG TCGGTGTCAACGGATTT- ${ }^{\prime}$, and antisense, 5' ${ }^{\prime}$-CACAGTCTTC TGAGTGGCAGTGAT- $3^{\prime}$. The identities of the bands obtained after PCR were confirmed by automated DNA sequencing (data not shown).

Caspase activity. Caspase activities were measured as described previously (Pervin et al, 2001; Singh et al, 2002). Control and treated cells were lysed in insect cell lysis buffer as described in for $30 \mathrm{~min}$ at $4{ }^{\circ} \mathrm{C}$. The lysates were used for caspase-3 $(3 \mu \mathrm{g})$, and caspase-9 $(6 \mu \mathrm{g})$ assays using Ac-DEVD-AMC and Ac-LEHDAMC (Pharmingen, San Diego, CA, USA) as caspase- 3 and caspase- 9 substrates, respectively. The released AMC after specific cleavage of respective substrates becomes fluorescent and were quantified using a fluorometer (Versa FluroTM, Bio-Rad) with excitation at $380 \mathrm{~nm}$ and emission at $440 \mathrm{~nm}$ for AMC substrates.

Downregulation of survivin by siRNA treatment. Synthetic siRNA targeting human survivin (Gene accession \# NM_001012271, Gene ontology, 4694) in MDA-MB-468 cells and random oligo VIII as a control for nonspecific siRNA effects were purchased from Dharmacon Research (Lafayette, CO, USA). Amaxa nucleofecter was used for the transfection $(\sim 85 \%$ efficiency) for $24 \mathrm{~h}$ following which the cells were treated with and without DETA-NONOate for another $24 \mathrm{~h}$. We also used another survivin siRNA (Dharmacon, NM_002759, Gene ontology, 6915) in some of our experiments to confirm the specificity of survivin siRNA and rule out the possibility of off-target siRNA effects in our experiments.

Overexpression of survivin. Full-length human survivin cDNA obtained from Gateway Entry clone (in Gateway vector; Invitrogen, Grand Island, NY, USA) was amplified by transformation in presence of $100 \mu \mathrm{g} \mathrm{ml}^{-1}$ Kanamycin. Survivin cDNA entry clone was transferred into Gateway Destination Vector PUC18 using LR Clonase system. Amplified clones were transfected into MDA-MB468 and HMLE HRAS cells using Transfectamine reagents under standard conditions (Pervin et al, 2003b).

Analysis of 8-iso-PGF2 $\alpha$ levels. Cells after various treatments were harvested by trysinisation, suspended in PBS ( $\mathrm{pH} 7.4$ ) containing $0.005 \%$ butylated hydroxytoluene and stored at $-80^{\circ} \mathrm{C}$. Total 8 -iso- $\mathrm{PGF}_{2 \alpha}$ levels in the cells were quantified using a direct 8 -iso-PGF2 $\alpha$ enzyme immunoassay kit from Assay Designs (Ann Arbor, MI, USA) according to the supplier's instructions. Briefly, hydrolysed samples were incubated with an 8 -iso-PGF $2 \alpha$ polyclonal antibody for $18 \mathrm{~h}$ and the colour was developed by incubation with $p$-nitrophenyl phosphate, which was read at $405 \mathrm{~nm}$.

Measurements of 4-hydroxy-trans-2-nonenal and 4-hydroxyalkenals. Oxidative stress was measured by 4-hydroxy-trans-2nonenal (4-HNE) using an ELISA kit (Cat\# STA-338, Cell Biolabs, San Diego, CA, USA) as well as 4-hydroxy-alkenals (4-HAE) using Aldetect Lipid Peroxidation Assay Kit (Enzo Life Sciences, Ann Arbor, MI, USA) as per manufacturer's instruction.

Tumour induction in ACI rats by oestrogen treatment. Six- to eight-week-old female ACI rats (purchased from Harlan SpragueDawley Inc., Indianapolis, IN, USA) were housed individually in an AAALAC-accredited facility under controlled temperature, humidity, 12 h light-dark cycles, provided with Teklad Rodent Diet 8604 and tap water ad libitum. The animal studies were carried out in adherence to the guidelines established in the Guide for the Care and Use of Laboratory Animals (US Department of Health and Human Resources, NIH, 1985) in the University of Kansas Medical
Center. After a 1-week acclimatisation period, rats were implanted subcutaneously with E2 pellets ( $3 \mathrm{mg}$ E2 $+17 \mathrm{mg}$ cholesterol), while rats in the control group were implanted with cholesterol pellets (17 mg cholesterol). At each of the time periods, the animals were killed using $\mathrm{CO}_{2}$ narcosis and the mammary tumours as well as normal mammary glands were fixed in formalin or snap frozen (Li et al, 2004; Weroha et al, 2010).

Xenograft formation. Six- to eight-week-old nude mice were purchased from Harlan Laboratories Inc., (Placentia, CA, USA) HMLE $^{\text {H-RAS }}$, MDA-MB-231 or MDA-MB-468 cells $\left(5 \times 10^{6}\right.$ cells $)$ suspended in $100 \mu \mathrm{l}$ matrigel were injected subcutaneously (10 mice per cell line) and tumour growth was monitored. Tumour volume was calculated as $1 / 2\left(\right.$ length $\times$ width $\left.^{2}\right)$ (Sancéau et al, 2002). Nude mice experiments were performed in accordance with Institutional Animal Care and Use Committee (IACUC) procedures and guidelines at Charles Drew University.

Cell fractionation. The cell fractionation was done using nuclear and cytoplasmic extraction reagents from Thermo Scientific, Rockford, IL, USA. The fractionation was done according to the manufacturer's protocol as described previously (Singh et al, 2009).

Statistical analysis. Data are presented as mean \pm s.d., and between-group differences were analysed using ANOVA. If the overall ANOVA revealed significant differences, then pairwise comparisons between groups were performed by Newman-Keuls multiple comparison test. All comparisons were two-tailed, and $P$-values $<0.05$ were considered statistically significant. The experiments were repeated at least three times, and data from representative experiments are shown.

\section{RESULTS}

Redistribution and downregulation of cellular survivin by OS in breast cancer cells. We have previously reported that OS induced upregulation of MKP-1 and inactivation of pERK1/2 in MDA-MB468 breast cancer cells and promoted apoptosis by Bax integration into mitochondrial membrane. Nitric oxide-donor DETA-NONOate was used to induce OS in MDA-MB-468 breast cancer cells. Since induction of MKP-1, an early stress-response gene, occurred between 3-6h of exposure to OS (Pervin et al, 2003a), we performed microarray analysis to examine key early targets of OS (data not shown). We found that although survivin mRNA expression was downregulated $(83.4 \pm 9.5 \%)$ at $16 \mathrm{~h}$ (Figure $1 \mathrm{~A}$ ); there was an early $(6 \mathrm{~h})$ decline $(68.4 \pm 12.9 \%)$ in cytosolic soluble survivin protein levels, which was associated with simultaneous increase in cytoplasmic MKP-1 (3.2 \pm 0.5 -fold) and membraneassociated survivin (2.2 \pm 0.7 -fold) levels (Figure 1B). However, total survivin protein levels (as assessed by lysing the cells in RIPA buffer) did not decline until 16-24h of NO treatment (Figure 1B). Downregulation of cellular survivin levels was analysed by immunofluorescence staining (Figure 1C). Cell fractionation studies show that survivin was located predominantly in the cytosol in untreated cells $(80.4 \pm 11.8 \%)$ and there was no significant change after NO treatment $(84.8 \pm 8.6 \%)$ (Figure 1D). However, when cellular localisation of survivin was examined by immunofluorescence staining, we noticed brighter aggregates or clumps of both cytosolic and nuclear survivin as early as $1 \mathrm{~h}$ of NO treatment (data not shown). Since activated pp38 MAPK has been reported to promote survivin downregulation (Engels et al, 2008), we also examined the levels of activated p38 MAPK at various time points of NO treatment. We found increased levels of pp38 MAPK after $16-24 \mathrm{~h}$ of NO treatment, which coincided with decreased cellular survivin protein and mRNA levels (Figure 1E). Our results therefore suggest that OS promotes early re-localisation and 
A

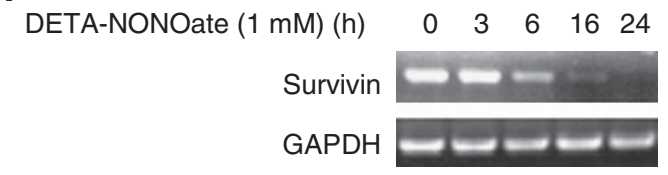

C
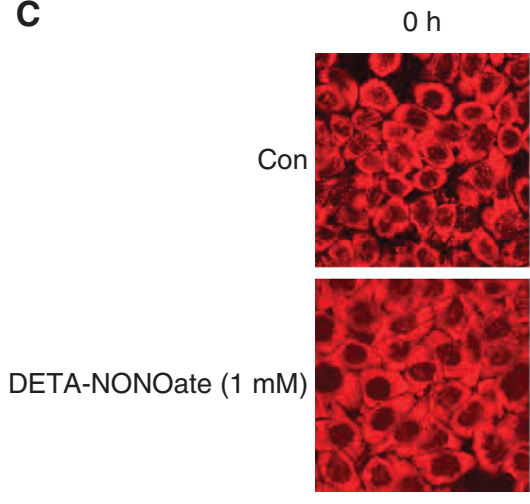

E

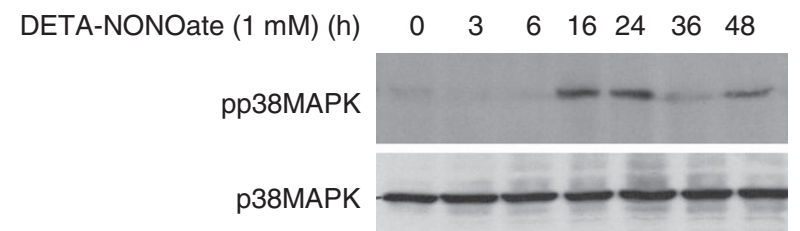

$24 \mathrm{~h}$
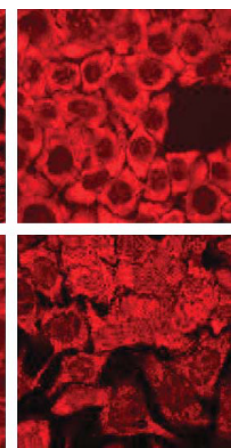

B DETA-NONOate $(1 \mathrm{mM})(\mathrm{h}) \quad \begin{array}{llllll}0 & 3 & 6 & 16 & 24\end{array}$

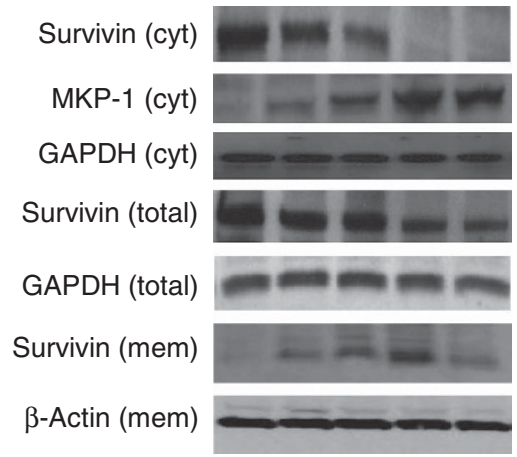

D

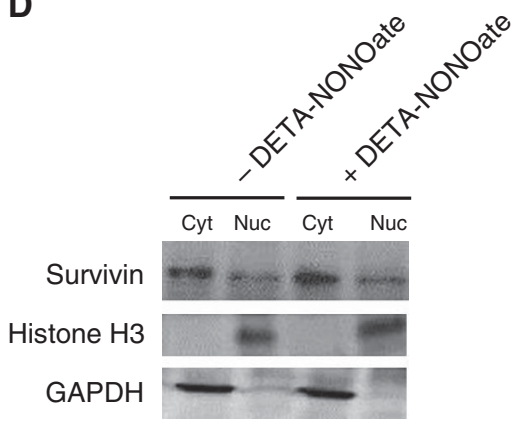

Figure 1. OS induces re-localisation and downregulation of survivin in MDA-MB-468 breast cancer cells. MDA-MB-468 cell line was grown to $80 \%$ confluence in six-well plates and treated with DETA-NONOate $(1 \mathrm{~mm})$ for various time points, after which (A) RNA was extracted and subjected to qPCR for survivin and GAPDH. (B) Total and cytosolic (cyt) survivin was extracted by suspending the cells in RIPA or MPER buffer respectively. Cytosolic extracts was subsequently suspended in RIPA buffer to extract membrane-bound survivin. Survivin in various cellular fractions was analysed by western blot analysis. (C) MDA-MB-468 cells were treated with DETA-NONOate (1 mM) and analysed by immunofluorescence using anti-survivin antibody. (D) Cells were subjected to cellular fractionation. Survivin, histone H3 (nuclear) and GAPDH (cytoplasmic) levels were detected in various fractions (Cyt, cytoplasmic or Nuc, nuclear) by western blot analysis. (E) Cells were subjected to western blot analysis using pp38MAPK or p38MAPK antibodies. Results are representative of three different experiments.

downregulation of cytosolic survivin in MDA-MB-468 breast cancer cells.

Survivin level in breast cancer cells determines the sensitivity to OS. Oxidative stress induced by DETA-NONOate (1 mM) treatment was measured by analysis of 8 -Iso-PGF $2 \alpha$ levels in MDA-MB-468 cells. We found a significant increase of 8-IsoPGF $2 \alpha$ levels in DETA-NONOate-treated cells after $16 \mathrm{~h}$ $(2.02 \pm 0.18$-fold) and $24 \mathrm{~h}$ ( $3.3 \pm 0.24$-fold) (Figure $2 \mathrm{~A})$. Oxidative stress in these cells were further analysed by measurement of lipid peroxide-mediated complex compounds such as malondialdehyde (MDA) and 4-hydroxy nonenal (4-HNE) (Figure 2B) as well as 4-hydroxy alkenal (4-HAE) (supplement Figure 1). We found a significant increase in the levels of MDA +4 -HNE after $16 \mathrm{~h}$ $(1.83 \pm 0.18$-fold $)$ and $24 \mathrm{~h}(3.57 \pm 0.24$-fold $)$ in DETA-NONOatetreated cells (Figure $2 \mathrm{~B}$ ). Since re-localisation of survivin preceded the induction of MKP-1, we reasoned that it could be a key event that may regulate cellular response to OS. To investigate whether survivin levels determined the sensitivity to OS, the basal levels of survivin was manipulated in MDA-MB-468 cells. Basal survivin levels were decreased by transfecting the cells with SMARTpool survivin small interfering RNAs (siRNA1 and siRNA2) or random siRNA obtained from Dharmacon. Western blot analysis showed a $75-80 \%$ reduction in survivin level with survivin siRNA treatments when compared with random siRNA (Figure 2C). When these cells were further exposed to various concentrations of NO (1-2 mM DETA-NONOate), we found that lower concentration of DETANONOate $(1 \mathrm{~mm})$ was sufficient to significantly reduce survivin $(72 \pm 9 \%)$ and increase MKP-1 levels $(2.4 \pm 0.4$-fold) after $6 \mathrm{~h}$
(Figure 2E). The increased sensitivity of these cells to NO-induced OS was further confirmed by analysing caspase- 3 and - 9 enzyme activities. Low concentration of NO-treatment was sufficient to induce both caspase- 3 and -9 activities in cells where survivin was downregulated by siRNA treatment (Figure 2D and F).

Since reduced survivin levels increased sensitivity of breast cancer cells to OS, we further examined whether overexpression of survivin would reduce the sensitivity. MDA-MB-468 cells were transfected with either empty vector or vector containing fulllength human survivin cDNA. The overexpression of survivin was confirmed by western analysis (Figure 2G). In survivin overexpressing MDA-MB-468 cells, a higher concentration of NO (2 mm DETA-NONOate) was required to reduce cytosolic survivin levels, upregulate MKP-1 (Figure 2H) and induce apoptosis (Figure 2D and F). These results suggest that cellular levels of survivin may determine the sensitivity of MDA-MB-468 cells to OS.

We next examined whether survivin levels regulated sensitivity to OS in other breast cancer cell lines. We utilised established breast cancer (ZR-75-30, BT474 and MDA-MB-231) and transformed mammary epithelial (HMLE ${ }^{\mathrm{H}-\mathrm{RAS}}$ ) cell lines to examine the relationship between survivin levels and cell's sensitivity to OS. The basal levels of survivin were found to vary within cell lines and 1 mM DETA-NONOate was sufficient to significantly downregulate the low levels of survivin in ZR 75-30 (Figure 3A) and induce apoptosis (Figure 3B). This amount of OS as produced by $1 \mathrm{~mm}$ DETA-NONOate was unable to significantly downregulate higher levels of survivin or induce apoptosis in all other cell lines studied (Figure 3B). Higher levels of OS were required for HMLE ${ }^{\mathrm{H}-\mathrm{RAS}}$ 
A

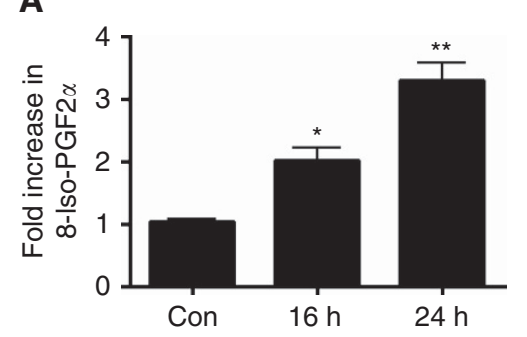

B

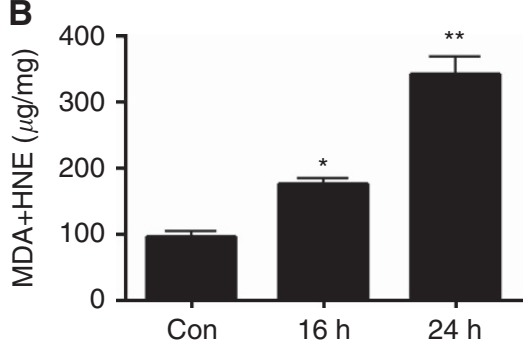

C

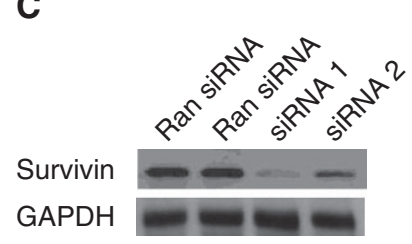

D

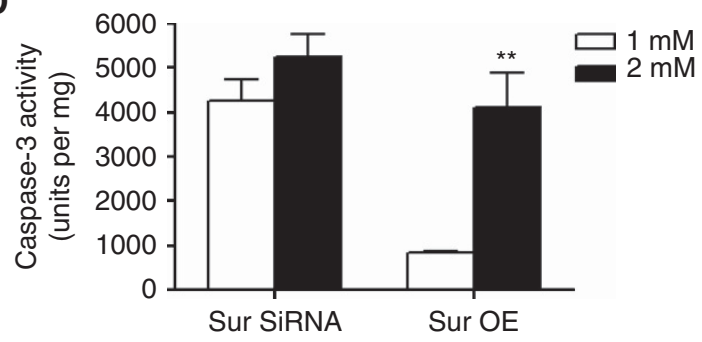

E

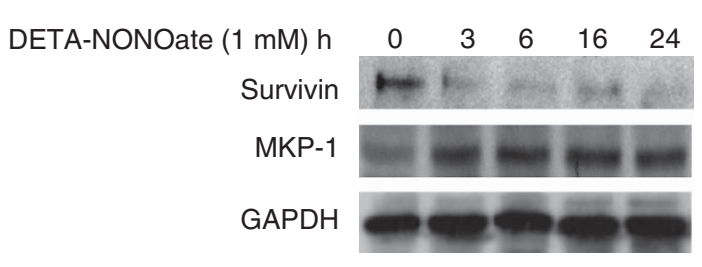

G

H
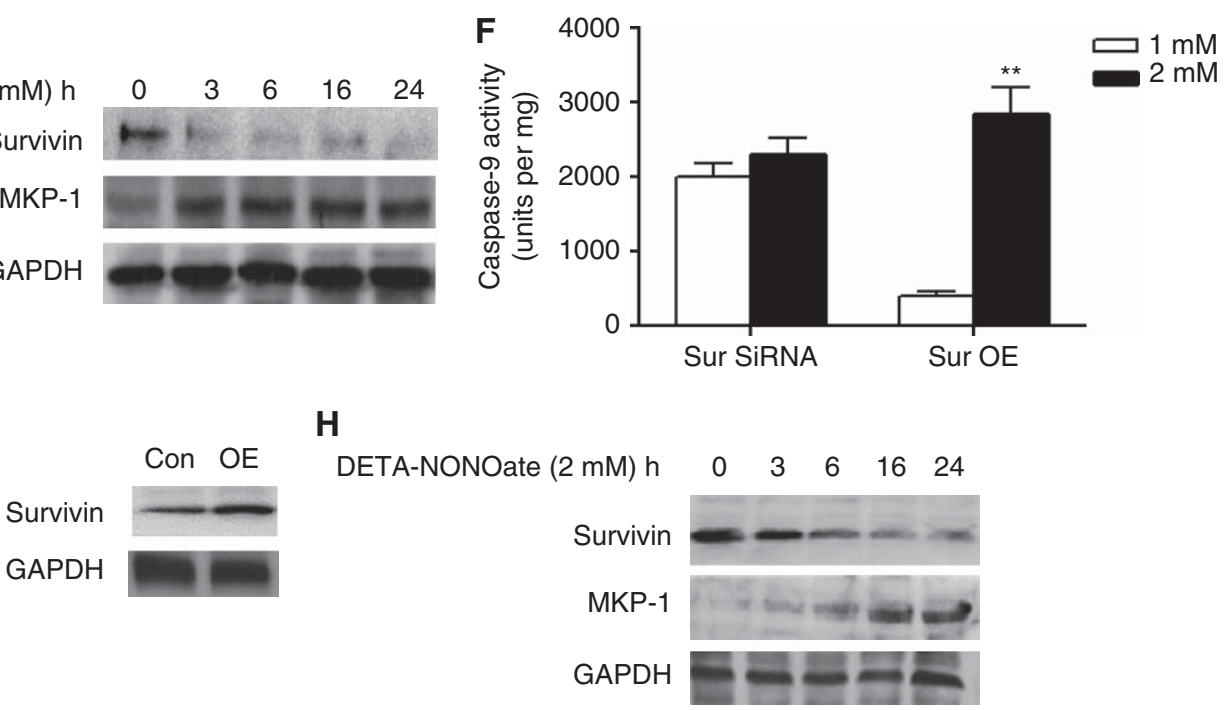

Figure 2. Survivin levels determine the sensitivity of MDA-MB-468 cells to OS. MDA-MB-468 cells were treated with DETA-NONOate for 16 or $24 \mathrm{~h}$ and OS was analysed by 8-Iso-PGE2 $\alpha$ (A) and MDA + HNE (B) analysis. (C) Cells were grown to $80 \%$ confluence in six-well plates were subjected to random (Ran siRNA) or small inhibitory RNAs (siRNA1 and 2) treatments followed by western blot analysis to examine survivin levels and (D) caspase-3 enzyme activity. (E) Treatment with DETA-NONOate (1 mM) for various time points and subjected to western blot analysis for survivin, MKP-1 and GAPDH. (G) Cells grown to $80 \%$ confluence were subjected to treatment with either control vector (Con) or full-length human survivin cDNA (Sur OE). (F) Caspase-9 activity of survivin OE and siRNA-treated cells. (H) Survivin overexpressing cells were further treated with DETA-NONOate $(2 \mathrm{~mm})$ for various time points and analysed by western blot for survivin and MKP-1 expression. ${ }^{\star \star} P \leqslant 0.01$. Results are representative of three different experiments.

(DETA-NONOate, $2 \mathrm{~mm}$ ) or BT474 (DETA-NONOate, $3 \mathrm{~mm}$ ) to downregulate survivin (Figure 3C) and induce apoptosis (Figure 3B). However, even 3-4 mM DETA-NONOate was insufficient to either downregulate survivin or induce apoptosis in MDA-MB-231 cells (Figure 3A and B). We observed that early reduction in the cytosolic survivin levels always preceded MKP-1 upregulation (Figure 3C, data for other cell lines not shown). A higher level of DETA-NONOate was not able to reduce survivin expression in MDA-MB-231 cells (Figure 3D). Our data, therefore, suggest that survivin levels determined the sensitivity to OS in various breast cancer cell lines examined and there was an inverse relationship between survivin and MKP-1, a sensor of OS.

Survivin expression was suppressed in high OS producing xenografts from human breast cancer cell lines. Since OS was found to downregulate survivin levels in human breast cancer cell lines in vitro, we further examined this relationship in various in vivo xenograft models in nude mice. It has been shown that Ras upregulates NOX 1, a NADPH oxidase to increase ROS which was necessary for Ras-mediated oncogenic transformation (Mitsushita et al, 2004). We generated transplantable xenografts by subcutaneous injection of HMLE ${ }^{\mathrm{H}-\mathrm{RAS}}$ cells in nude mice. When early (1-7 weeks) and late (10-15 weeks) xenografts from HMLE $^{\mathrm{H}-\mathrm{RAS}}$ cells were examined, we found significantly higher levels of OS as measured by 8 -Iso PGF $2 \alpha$ levels ( $1 \mathrm{~W}: 2.1 \pm 0.3$; $3 \mathrm{~W}$ : $3.8 \pm 0.6$; $5 \mathrm{~W}: 6.9 \pm 1.6$; $7 \mathrm{~W}: 4.2 \pm 0.8$-fold $)$ in early xenografts $(\sim 0.1-0.3 \mathrm{~cm})$ compared with the larger $(\sim 0.8-1.2 \mathrm{~cm})$ xenografts at later time points (Figure 4A). We also measured MDA + HNE (Figure 2B) and MDA + HAE (supplement Figure 2) in various stages of $\mathrm{H}$-Ras-induced xenografts. We found a significant increase in OS in 3 weeks ( $1.61 \pm 0.37$-fold) and 5 weeks xenografts $(3.07 \pm 0.24$-fold) (Figure $4 \mathrm{~B})$. Since there was high OS in xenografts obtained from early stage tumours, we further examined the expression of various NADPH oxidases (NOX1, NOX2 and 
A

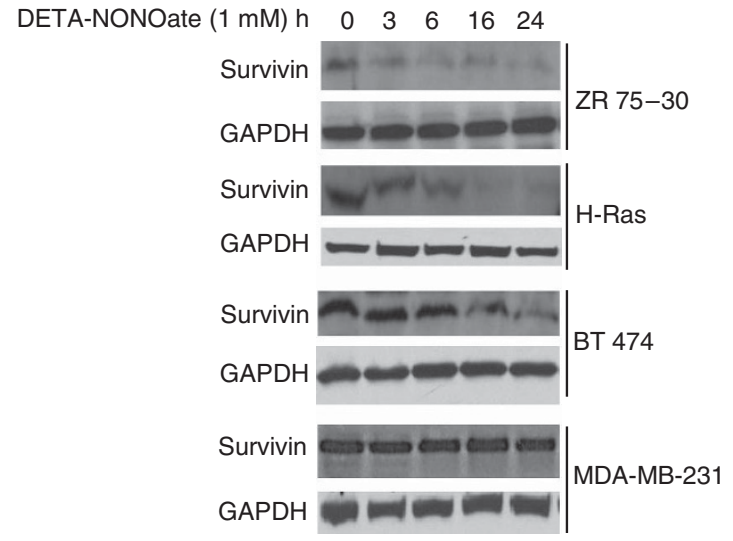

B

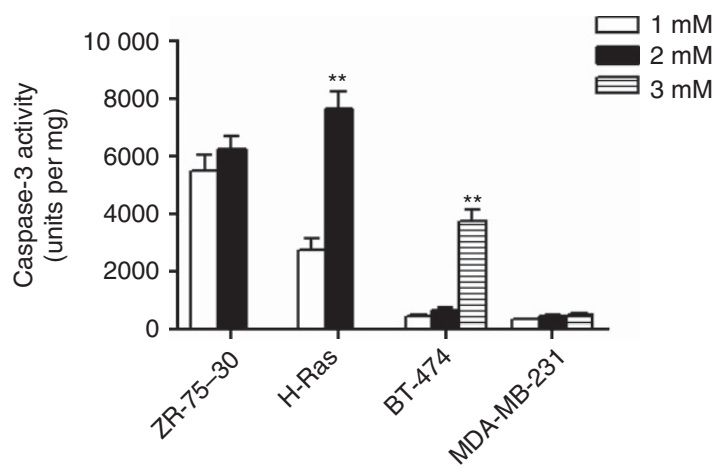

C

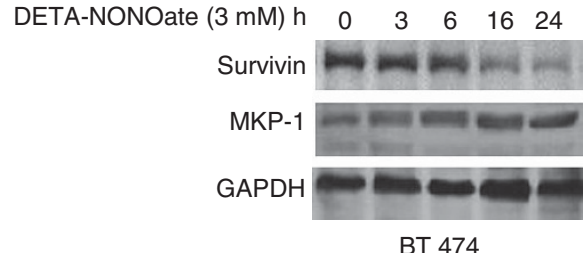

D

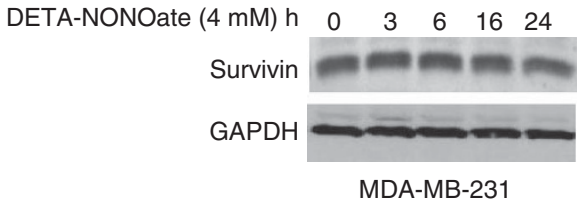

Figure 3. OS induces downregulation of survivin in breast cancer cells and increases their sensitivity. Cells were treated with various concentration of DETA-NONOate (1-4 mM) for various time points and analysed for (A) Survivin expression by western blot analysis (1 mM DETANOnoate) (B) Caspase-3 enzymatic activity (C) Survivin and MKP-1 protein expression (3 mM DETA-NONOate) and (D) Survivin protein expression ( $4 \mathrm{~mm}$ DETA-NONOate) by western blot analysis. ${ }^{*} P \leqslant 0.01$ (compared with $1 \mathrm{~mm}$ treatment group). Results are representative of three different experiments.

NOX4) and their regulatory subunits (p67 and p47) that have been implicated in the production of OS (Mitsushita et al, 2004). There was high expression of NOX1 and p67 (Figure 4C) in early xenografts, in addition to $\mathrm{p} 47$, another regulatory subunit of NADPH oxidase (data not shown). Importantly, these early xenografts with high levels of OS expressed low levels of survivin, which were highly upregulated in larger xenografts at later time points. In addition, pERK1/2, which has been implicated in promoting the progression of breast tumours, was upregulated in larger xenografts (Figure 4C). The level of cleaved caspase-3 was higher in early xenografts compared with the larger ones (Figure 4C). To examine whether downregulation of survivin was an important event in OS-mediated tumour initiation, we overexpressed survivin in HMLE ${ }^{\mathrm{H}-\mathrm{RAS}}$ cells. Survivin overexpression reduced NOX1 protein expression and reduced tumour volume when injected in nude mice (Figure 4D-E).

We further examined the xenografts from survivin high (MDAMB-231) and low (MDA-MB-468) expressing cell lines. Xenograft from MDA-MB-231 cell line expressed lower OS as measured by 8 -iso-PGE $2 \alpha$ levels (Figure $4 \mathrm{~F}$ ) and higher levels of survivin protein expression (Figure 4F) when compared with xenografts from MDA-MB-468 cells. Also, OS markers NOX1 and NOX4 as well as MKP-1 levels were higher in xenografts from MDA-MB-468 when compared to those from MDA-MB-231 cells (Figure 4G). Our data, therefore, suggest that high OS suppresses survivin expression in in vivo xenograft models of breast tumours.

Survivin expression was suppressed while OS was high in E2induced mammary tumours in female ACI rats. We further examined female ACI rats, which are sensitive to oestrogen and give rise to E2-induced sporadic ductal breast cancers (SDBC) that remarkably reflects the molecular and histopathology that is observed in human (Li et al, 2004; Weroha et al, 2010). Oestrogen treatment of these rats promotes development of atypical ductal hyperplasia $(\mathrm{ADH})$ at $3 \mathrm{~m}$, while at 4.5 and 6 months there is formation of ductal carcinoma in situ (DCIS) and mammary tumours in the mammary gland, respectively. High OS has been reported in E2-induced mammary tumours in ACI rats (Li et al, 2004; Weroha et al, 2010). Using this model, we examined the levels of OS, which was increased as early as 3 months of E2 treatment (Figure 5A). We analysed the expression levels of NOX1 and its activators p67 and p47 using both immunohistochemistry (Figure 5B) and western blot analysis (Figure 5C). NOX1, p67 and p47 were induced as early as 3 months of E2 treatment and remained upregulated throughout tumour progression (3-6 months). Furthermore, these changes were associated with low levels of survivin and increased levels of MKP-1 throughout tumour formation (Figure 5C). Also, there was increased caspase- 3 activity (data not shown) and cleaved caspase- 3 as detected by western blot analysis in ADH, DCIS and tumours in this model of E2-induced tumours (Figure 5C). Our data, therefore, suggest that high OS suppresses survivin expression in E2-induced breast tumours in ACI rats.

Reduced survivin expression in human breast tumours with high levels of NOX1/p67/p47. In various human breast tumours, particularly those that are ER + , high amounts of OS has been found to promote tumour progression. We analysed the levels of OS-generating enzymes NOX1, and p67 as well as MKP-1 and survivin levels in ER + and $\mathrm{TN}$ human breast tumours by immunohistochemistry and western blot analysis. We stained paraffin-embedded sections from 104 pathologically characterised human breast tumours of which 63 were ER + , while 41 were from TN. Consecutive sections from each patient were stained with NOX1 (Figure 6A), p67 (Figure 6B) and survivin (Figure 6C). We found a significant increase in NOX1 (3.6 \pm 0.8 -fold) (Figure 6A) and p67 (2.4 \pm 0.7 -fold) (Figure 6B) in ER + tumours compared with the TN tumours. On the other hand, expression of survivin was found to be significantly decreased $(59.4 \pm 8.7 \%)$ in ER + tumours compared with the TN tumours (Figure 6C). We also 


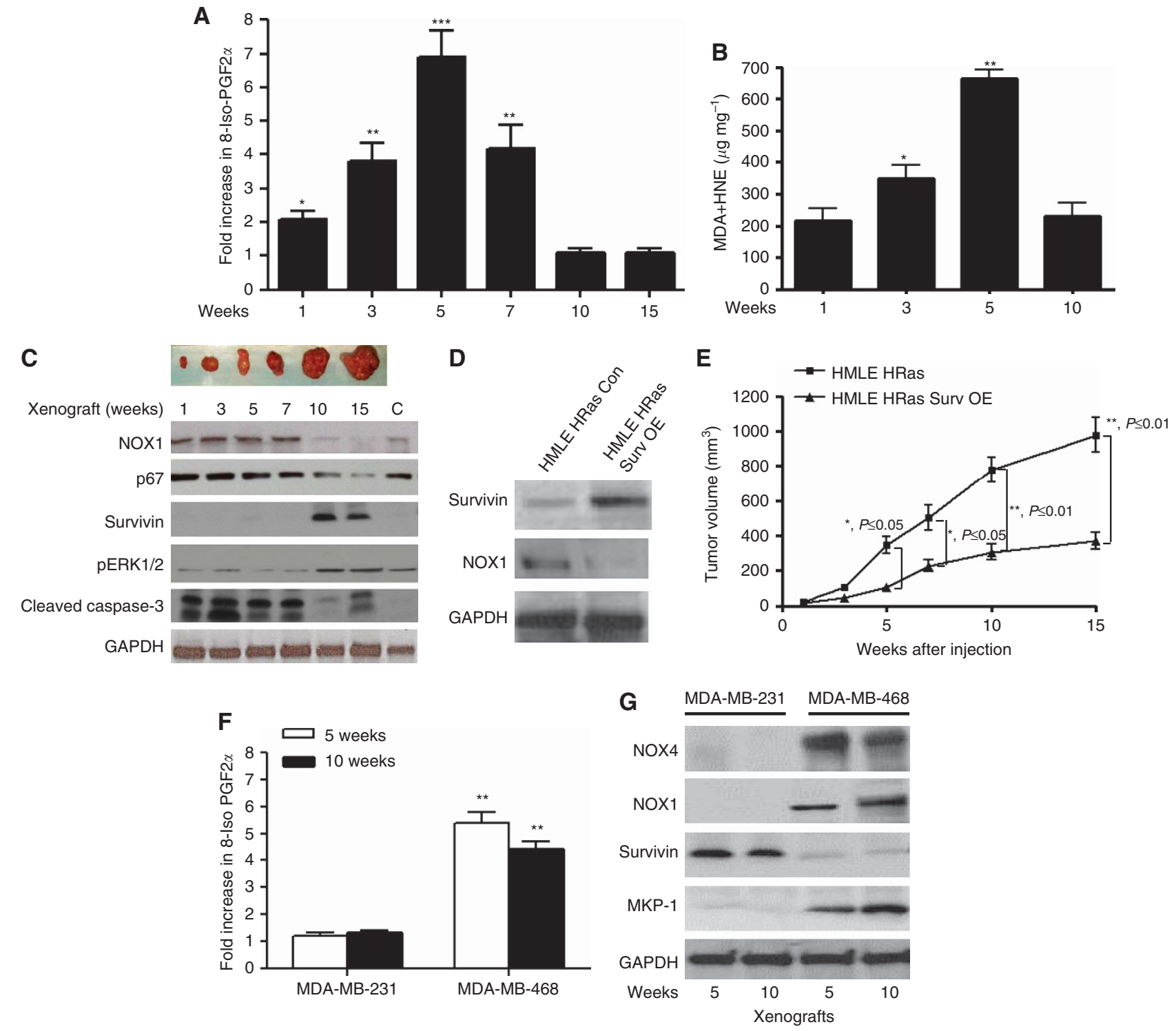

Figure 4. Survivin levels remain suppressed in in vivo xenografts in nude mice where OS remains elevated. HMLE HRAS cells $\left(5 \times 10^{6}\right.$ cells) were subcutaneously injected in nude mice and the xenografts grown for various time points were subjected to (A) 8 -iso-PGF2 $\alpha$ analysis or (B) MDA + HNE analysis. (C) Top panel: pictographs of xenografts obtained after various time points. Bottom panel: NOX1, p67, survivin, pERK1/2, cleaved caspase-3 and GAPDH analysis by western blot. (D) Overexpression of control vector (Con) or full-length survivin (Surv OE) in HMLE HRAS cells and analysis of NOX1 protein expression by western blot analysis (E) Control and Surv OE cells were subcutaneously injected in nude mice. Tumour volumes were analysed after various time points. (F) MDA-MB-231 and MDA-MB-468 breast cancer $\left(5 \times 10^{6}\right)$ cells were injected in nude mice and the xenografts grown for various time points were subjected to 8-iso-PGF2 $\alpha$ analysis and (G) NOX1, NOX4, survivin, MKP-1 and GAPDH protein expression by western blot analysis. ${ }^{\star} P \leqslant 0.05,{ }^{\star \star} P \leqslant 0.01$ and ${ }^{\star \star \star} P \leqslant 0.001$. Results are representative of three different experiments.

performed western blot analysis using $25 \mathrm{TN}$ (five samples pooled in each lane) and $20 \mathrm{ER}+$ (five samples pooled in each lane) frozen human breast tumours. We found a significant increase in NOX1 (4.2 \pm 0.8 -fold), p67 (3.7 \pm 0.6 -fold) and MKP-1 (2.8 \pm 0.6 fold); while survivin levels was found to be significantly declined by $67.4 \pm 9.2 \%$ (Figure 6D). Our data, therefore, suggest that OSgenerating proteins are upregulated while survivin levels remain downregulated in $\mathrm{ER}+$ compared with $\mathrm{TN}$ human breast tumours.

\section{DISCUSSION}

Oestrogens have been strongly implicated in the genesis of most frequently diagnosed SDBC in women (Cavalieri et al, 2002; Geyer et al, 2012). Since these tumours are more dependent than TN breast tumours on their microenvironment for development, they remain difficult to propagate both in vitro and in vivo (Pervin et al, 2010; Mohibi et al, 2011). Although the microenvironment of these SDBC still remains poorly understood, it has been demonstrated that OS plays a key role in their initiation and progression (Shinohara et al, 2010; Toullec et al, 2010). Oxidative stress has been reported to activate key signal transduction pathways to increase proliferation of cancer cells in a concentration-dependent manner (Afanas'ev et al, 2011). In this study, we show for the first time that OS promotes early and sustained downregulation of survivin, which could be an important event, particularly during initiation of some human mammary tumours. This inverse relationship between high OS and survivin was found in HMLE $^{\mathrm{H}-\mathrm{RAS}}$ cell-induced xenografts, in E2-induced mammary tumours in ACI rats, and also human breast tumours. In 
A

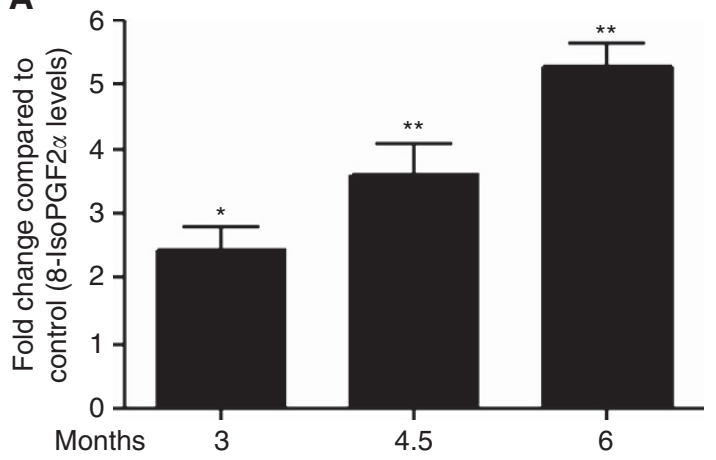

B
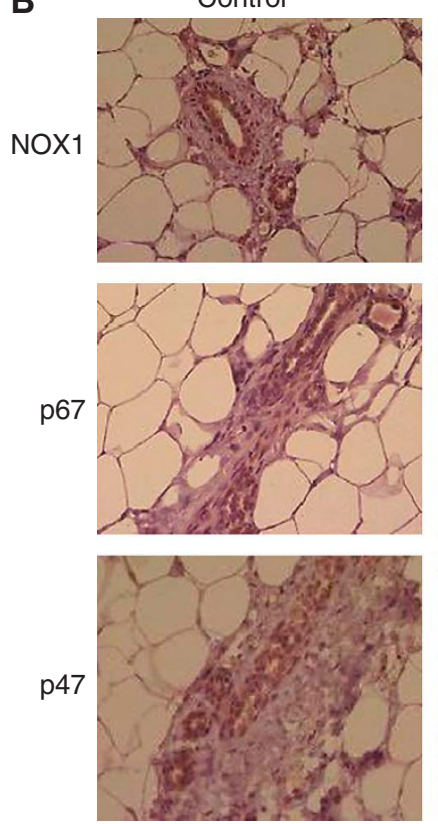

ADH
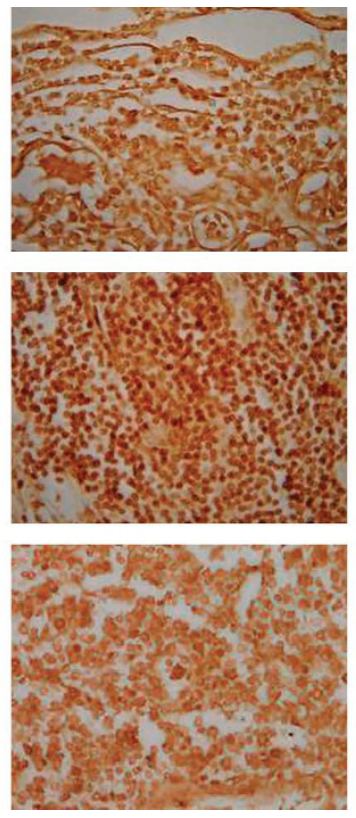

DCIS
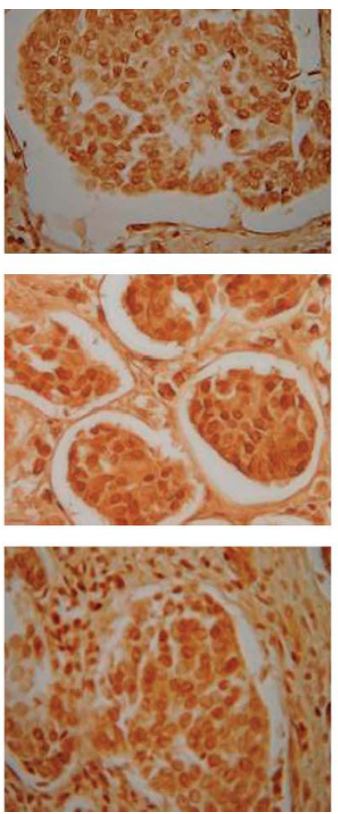

Tumours
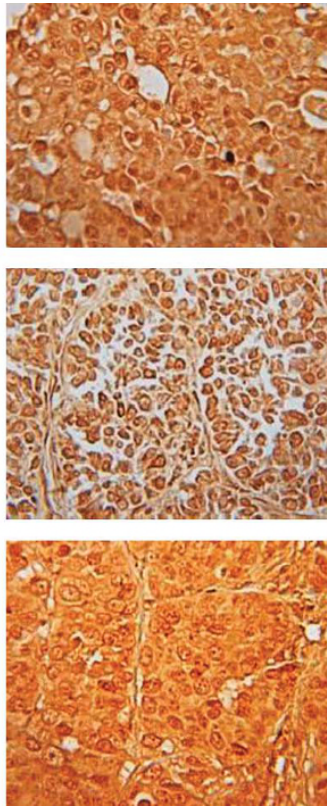

C

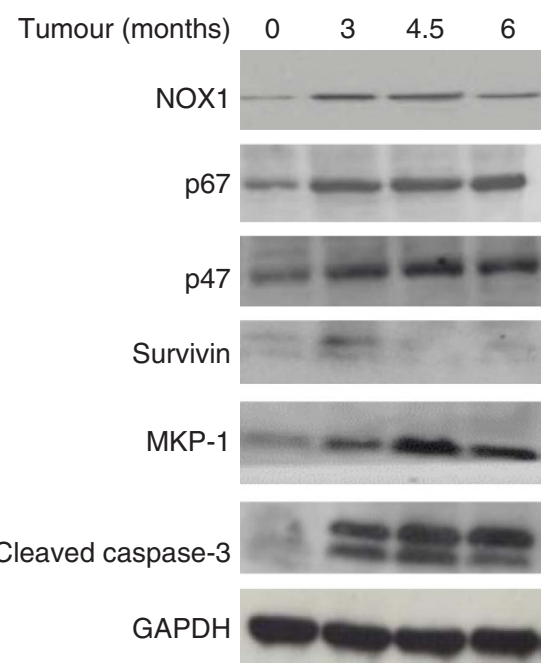

E2-induced mammary tumours ( $\mathrm{ACl}$ rat)

Figure 5. Survivin levels remain suppressed in E2-induced mammary tumours in $\mathrm{ACl}$ rats. $\mathrm{ACl}$ rats treated with $\mathrm{E} 2$ pellets for various time points (0-6 months) were subjected to (A) 8-iso-PGF2 $\alpha$ analysis (B) Paraffin-embedded control and tumour sections at various stages (ADH $=$ atypical ductal hyperplasia; DCIS = ductal carcinoma in situ; and tumours) were subjected to immunohistochemical analysis using NOX1, p67 or p47 antibodies. (C) Detection of NOX1, p67, p47, survivin and MKP-1 expression by western blot analysis. ${ }^{\star} P \leqslant 0.05$, ${ }^{\star \star} P \leqslant 0.01$ and ${ }^{\star \star \star} P \leqslant 0.01$ (compared with control group). Results are representative of three different experiments. 
A

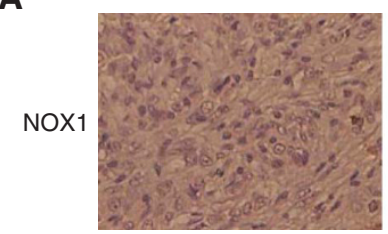

B

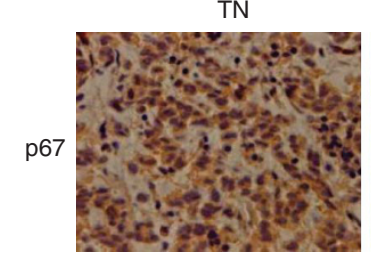

C

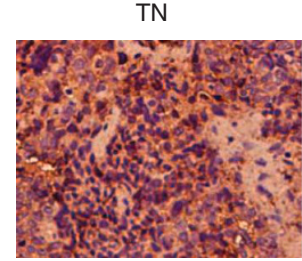

ER+

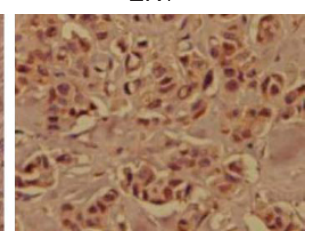

$\mathrm{ER}+$

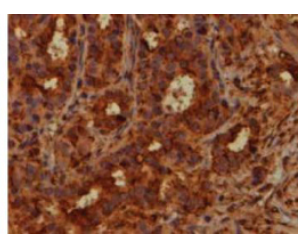

$\mathrm{ER}+$

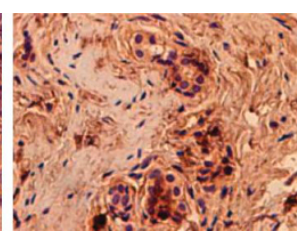

Nox1

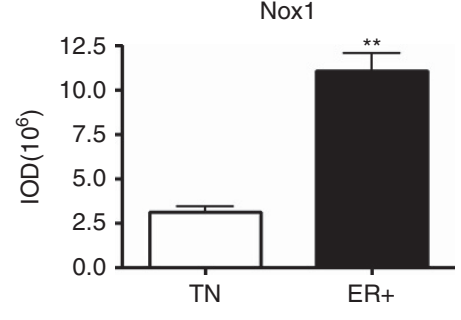

p67
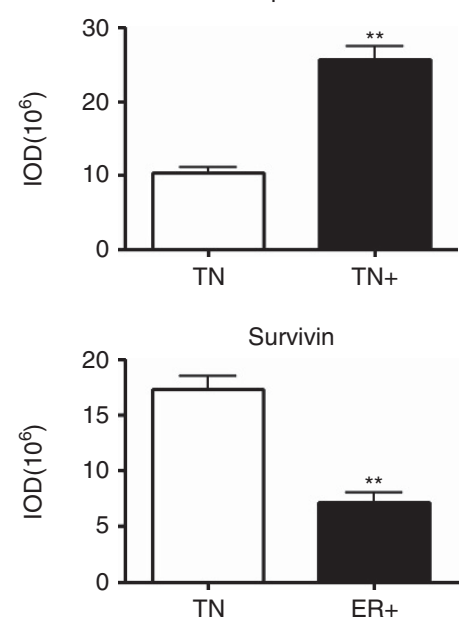

D TN ER+
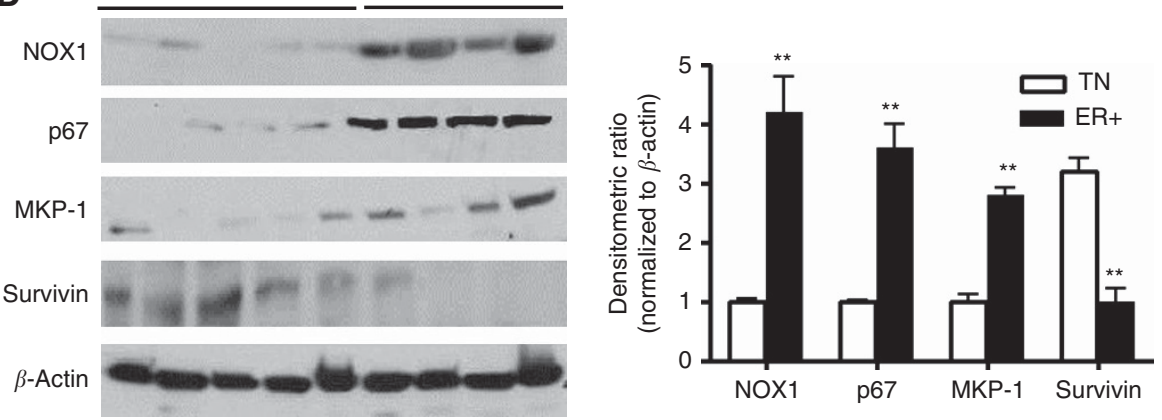

Figure 6. Survivin levels remain suppressed in human breast tumours where NOX1 and p67 expression was high. Paraffin-embedded tumour sections from $\mathrm{TN}$ and $\mathrm{ER}^{+}$human breast tumours were analysed by immunohistochemical analysis (left panels, A-C), (A) anti-NOX1 (B) anti-p67 or (C) anti-survivin antibodies. (right panels, A-C) Quantitative image analysis demonstrating relative abundance of specific proteins (D) left panel, $50 \mu \mathrm{g}$ of pooled (five each) tumour lysates obtained from frozen human tumours were subjected to western blot analysis using NOX1, p67, MKP-1, survivin and $\beta$-actin antibodies. Right panel, normalised densitometric ratios. ${ }^{\star \star} P \leqslant 0.01$ (compared with TN group).

HMLE $^{\text {H-RAS }}$ cell-induced xenografts high OS and low survivin was found in the initial stages when tumour volume was small. Whereas during later stages with increased tumour growth, the OS levels declined. However, in E2-induced tumours in ACI rat model, high OS persisted throughout tumour formation while survivin levels remained low.

In addition to mitochondria, NADPH oxidase-dependent ROS signalling regulates key cellular processes like proliferation, angiogenesis, cell-cycle arrest and apoptosis in many types of cancer (Ray et al, 2012). NOX1 is a member of NADPH oxidases (NOX) family, which are membrane-associated flavoprotein complexes that have homology to the catalytic subunit of respiratory burst oxidase (Shinohara et al, 2007). NOX1 expression is induced by Ras-MEK-MAPK pathway and NOX1-generated ROS promote angiogenesis among other tumourigenesis related events (Sumimoto et al, 2008). Our study confirms other findings that NOX1, which is upregulated in HMLE ${ }^{\text {HRAS }}$ cells and produces OS to promote tumour formation (Mitsushita et al, 2004;
Sumimoto et al, 2008). We also demonstrate that NOX1 was upregulated in early xenografts, including all stages of E2-induced SDBC in ACI rats and human breast tumours that are predominantly ER + . Members of NOX family form stable heterodimer with membrane protein $\mathrm{p} 22^{\text {phox }}$, a docking site for the $\mathrm{SH} 3$ domain-containing regulatory proteins $\mathrm{p} 47$ and $\mathrm{p} 67$, which serve as a switch for NOX activation (Shinohara et al, 2007). We show for the first time that p67 and p47 were highly upregulated in ER + human breast tumours when compared with the ER - tumours. Interestingly, in contrast to NOX1, we find TN breast cancer cell line MDA-MB-468 (Figure 4F) and some TN human breast tumours express very high levels of NOX4, which is when downregulated reduced the tumour formation, confirming the importance of OS during the process (Pervin et al, unpublished results).

It has been well demonstrated that OS in concentrationdependent manner regulates aggressive tumour behaviour like proliferation and angiogenesis in cancer cells (Afanas'ev et al, 
2011). In these reports, low levels of OS promote proliferation by activating ERK1/2 and Akt pathways while higher levels activate p38MAPK to induce apoptosis (Kim et al, 2011). Our data, therefore, support these findings because only in larger xenografts, a decline in OS increased activated pERK1/2 levels. In all stages of E2-induced SDBC in ACI rats, increased levels of cleaved caspase-3 and pp38MAPK could be associated with low levels survivin that persisted throughout tumour formation. However, in the xenograft model, although there were higher levels of cleaved caspase- 3 in earlier smaller tumours compared with later stages, induction of apoptosis in certain cell types appears to be a constant feature in OS-mediated mammary tumours.

It has been shown that survivin levels remain downregulated when high OS induces apoptosis (White-Gilbertson et al, 2009; Ahamed et al, 2011). Our findings further provide strong evidences that OS specifically induce early downregulation of survivin in human breast cancer cell lines. Unique positioning of survivin in cancer cells has enabled it to link together multiple functional molecular networks to promote aggressive behaviour (Kanwar et al, 2011). There are reports that high survivin promotes xenograft formation and its downregulation slows tumour growth (Mesri et al, 2001; Li et al, 2006). These experiments were mostly performed with aggressive cell lines that probably do not require OS for tumour initiation.

Due to a tight association between high OS and survivin in our studies, we have been unable to delineate the significance of one in the absence of other. Since significant apoptosis occurs in OSmediated tumours even when survivin levels were high in xenograft model, we can only speculate the importance of reduced survivin in this process. There is high probability that reduced survivin could promote induction of aneuploidy in certain types of cells during the initial stages that could increase breast tumour formation. A direct causal link between oestrogen and induction of chromosomal instability and aneuploidy has been reported in oestrogen-associated neoplasms (Li et al, 2003).

Since OS plays an important role in E2-induced tumours, we conclude that downregulation of survivin could be an important early step in their initiation and progression by promoting induction of aneuploidy.

\section{ACKNOWLEDGEMENTS}

We are grateful to Dr Jonathan J Li (Kansas Medical Center) for his generous help with fresh, frozen and paraffin-embedded sections from oestrogen-induced tumours in ACI rats and stimulating discussions related to tumour initiation and development in ACI rat model. We are also grateful to Dr Robert Weinberg (Whitehead Institute, Harvard Medical Center) for providing HMLE and HMLE $^{\text {HRAS }}$ cells and Dr Srinivasa T Reddy for his helpful advice with lipid peroxidation assays. The work was supported by $\mathrm{NIH}$ Grants 1SC1 CA165865-01A1 (SP), SC1 AG033407-01A1 (RS), and in part by U54CA143931. This manuscript is dedicated to the loving memory of Dr Jonathan $\mathrm{J} \mathrm{Li}$, who passed away during the progress of this work.

\section{REFERENCES}

Adamkov M, Halasova E, Kajo K, Machalekova K, Vybohova D, Varga I, Rajcany J (2010) Survivin: a promising biomarker in breast carcinoma. Neoplasma 57: 572-577.

Afanas'ev I (2011) Reactive oxygen species signaling in cancer: comparison with aging. Aging Dis 2: 219-230.

Ahamed M, Akhtar MJ, Raja M, Ahmad I, Siddiqui MK, AlSalhi MS, Alrokayan SA (2011) ZnO nanorod-induced apoptosis in human alveolar adenocarcinoma cells via p53, survivin and bax/bcl-2 pathways: role of oxidative stress. Nanomedicine 7: 904-913.

Braga M, Bhasin S, Jasuja R, Pervin S, Singh R (2012) Testosterone inhibits transforming growth factor- $\beta$ signaling during myogenic differentiation and proliferation of mouse satellite cells: potential role of follistatin in mediating testosterone action. Mol Cell Endocrinol 350: 39-52.

Cavalieri EL, Rogan EG (2002) A unified mechanism in the initiation of cancer. Ann NY Acad Sci 959: 341-354.

Coso S, Harrison I, Harrison CB, Vinh A, Sobey CG, Drummond GR, Williams ED, Selemidis S (2012) NADPH oxidases as regulators of tumor angiogenesis: current and emerging concepts. Antioxid Redox Signal 16: 1229-1247.

Desouki MM, Kulawiec M, Bansal S, Das GM, Singh KK (2005) Cross talk between mitochondria and superoxide generating NADPH oxidase in breast and ovarian tumors. Cancer Biol Ther 4: 1367-1373.

Engels K, Knauer SK, Loibl S, Fetz V, Harter P, Schweitzer A, Fisseler-Eckhoff A, Kommoss F, Hanker L, Nekljudova V, Hermanns I, Kleinert H, Mann W, du Bois A, Stauber RH (2008) NO signaling confers cytoprotectivity through the survivin network in ovarian carcinomas. Can Res 68: 5159-5166.

Geyer FC, Rodrigues DN, Weigelt B, Reis-Filho IS (2012) Molecular classification of estrogen receptor-positive/luminal breast cancers. $A d v$ Anat Pathol 19: 39-53.

Jha K, Shukla M, Pandey M (2012) Survivin expression and targeting in breast cancer. Surg Oncol 21: 125-131.

Kanwar JR, Kamalapuram SK, Kanwar RK (2011) Targeting survivin in cancer: the cell-signalling perspective. Drug Discov Today 16: 485-494.

Karihtala P, Kauppila S, Puistola U, Jukkola-Vuorinen A (2011) Divergent behaviour of oxidative stress markers 8-hydroxydeoxyguanosine (8-OHdG) and 4-hydroxy-2-nonenal (HNE) in breast carcinogenesis. Histopathology 58: 854-862.

Kim JY, Yu SJ, Oh HJ, Lee JY, Kim Y, Sohn J (2011) Panaxydol induces apoptosis through an increased intracellular calcium level, activation of JNK and p38 MAPK and NADPH oxidase-dependent generation of reactive oxygen species. Apoptosis 16: 347-358.

Korkaya H, Liu S, Wicha MS (2011) Regulation of cancer stem cells by cytokine networks: attacking cancer's inflammatory roots. Clin Cancer Res 17: 6125-6129.

Li JJ, Li SA (2003) Causation and prevention of solely estrogen-induced oncogenesis: similarities to human ductal breast cancer. Adv Exp Med Biol 532: 195-207.

Li JJ, Weroha SJ, Lingle WL, Papa D, Salisbury JL, Li SA (2004) Estrogen mediates Aurora-A overexpression, centrosome amplification, chromosomal instability, and breast cancer in female ACI rats. Proc Natl Acad Sci USA 101: 18123-18128.

Li QX, Zhao J, Liu JY, Jia LT, Huang HY, Xu YM, Zhang Y, Zhang R, Wang CJ, Yao LB, Chen SY, Yang AG (2006) Survivin stable knockdown by siRNA inhibits tumor cell growth and angiogenesis in breast and cervical cancers. Cancer Biol Ther 5: 860-866.

Li Y, Ambrosone CB, McCullough MJ, Ahn J, Stevens VL, Thun MJ, Hong CC (2009) Oxidative stress-related genotypes, fruit and vegetable consumption and breast cancer risk. Carcinogenesis 30: 777-784.

Li Z, Yang S, Chang T, Cao X, Shi L, Fang G (2012) Anti-angiogenesis and anticancer effects of a plasmid expressing both ENDO-VEGI151 and small interfering RNA against survivin. Int J Mol Med 29: 485-490.

Mense SM, Singh B, Remotti F, Liu X, Bhat HK (2009) Vitamin C and alphanaphthoflavone prevent estrogen-induced mammary tumors and decrease oxidative stress in female ACI rats. Carcinogenesis 30: 1202-1208.

Mesri M, Wall NR, Li J, Kim RW, Altieri DC (2001) Cancer gene therapy using a survivin mutant adenovirus. J Clin Invest 108: 981-990.

Mitsushita J, Lambeth JD, Kamata T (2004) The superoxide-generating oxidase Nox1 is functionally required for Ras oncogene transformation. Cancer Res 64: 3580-3585.

Mobley JA, Brueggemeier RW (2004) Estrogen receptor-mediated regulation of oxidative stress and DNA damage in breast cancer. Carcinogenesis 25: 3-9.

Mohibi S, Mirza S, Band H, Band V (2011) Mouse models of estrogen receptor-positive breast cancer. J Carcinog 10: 35.

Muchmore SW, Chen J, Jakob C, Zakula D, Matayoshi ED, Wu W, Zhang H, Li F, Ng SC, Altieri DC (2000) Crystal structure and mutagenic analysis of the inhibitor-of-apoptosis protein survivin. Mol Cell 6: 173-182.

Oliveras-Ferraros C, Vazquez-Martin A, Cufí S, Torres-Garcia VZ, Sauri-Nadal T, Barco SD, Lopez-Bonet E, Brunet J, Martin-Castillo B, Menendez JA (2011) Inhibitor of Apoptosis (IAP) survivin is 
indispensable for survival of HER2 gene-amplified breast cancer cells with primary resistance to HER1/2-targeted therapies. Biochem Biophys Res Commun 407: 412-419.

Panis C, Victorino VJ, Herrera AC, Freitas LF, De Rossi T, Campos FC, Simão AN, Barbosa DS, Pinge-Filho P, Cecchini R, Cecchini AL (2012) Differential oxidative status and immune characterization of the early and advanced stages of human breast cancer. Breast Cancer Res Treat 133: 881-888.

Perou CM, Børresen-Dale AL (2011) Systems biology and genomics of breast cancer. Cold Spring Harb Perspect Biol 3: pii a003293.

Pervin S, Chaudhuri G, Singh R (2010) NO to breast: when, why and why not? Curr Pharm Des 16: 451-462.

Pervin S, Singh R, Chaudhuri G (2003b) Nitric-oxide-induced Bax integration into the mitochondrial membrane commits MDA-MB-468 cells to apoptosis: essential role of Akt. Cancer Res 63: 5470-5479.

Pervin S, Singh R, Freije WA, Chaudhuri G (2003a) MKP-1-induced dephosphorylation of extracellular signal-regulated kinase is essential for triggering nitric oxide-induced apoptosis in human breast cancer cell lines: implications in breast cancer. Cancer Res 63: 8853-8860.

Pervin S, Singh R, Gau CL, Edamatsu H, Tamanoi F, Chaudhuri G (2001) Potentiation of nitric oxide-induced apoptosis of MDA-MB-468 cells by farnesyltransferase inhibitor: implications in breast cancer. Cancer Res 61: 4701-4706.

Pervin S, Tran AH, Zekavati S, Fukuto JM, Singh R, Chaudhuri G (2008) Increased susceptibility of breast cancer cells to stress mediated inhibition of protein synthesis. Cancer Res 68: 4862-4874.

Polyak K (2011) Heterogeneity in breast cancer. J Clin Invest 121: 3786-3788.

Poyton RO, Ball KA, Castello PR (2009) Mitochondrial generation of free radicals and hypoxic signaling. Trends Endocrinol Metab 20: 332-340.

Quong J, Eppenberger-Castori S, Moore 3rd D, Scott GK, Birrer MJ, Kueng W, Eppenberger U, Benz CC (2002) Age-dependent changes in breast cancer hormone receptors and oxidant stress markers. Breast Cancer Res Treat 76: 221-236.

Ray PD, Huang BW, Tsuji Y (2012) Reactive oxygen species (ROS) homeostasis and redox regulation in cellular signaling. Cell Signal 24: 981-990.

Sancéau J, Poupon MF, Delattre O, Sastre-Garau X, Wietzerbin J (2002) Strong inhibition of Ewing tumor xenograft growth by combination of human interferon-alpha or interferon-beta with ifosfamide. Oncogene 21: 7700-7709.

Sharhar S, Normah H, Fatimah A, Fadilah RN, Rohi GA, Amin I, Cham BG, Rizal RM, Fairulnizal MN (2008) Antioxidant intake and status, and oxidative stress in relation to breast cancer risk: a case-control study. Asian Pac J Cancer Prev 9: 343-349.

Shinohara M, Adachi Y, Mitsushita J, Kuwabara M, Nagasawa A, Harada S, Furuta S, Zhang Y, Seheli K, Miyazaki H, Kamata T (2010) Reactive oxygen generated by NADPH oxidase 1 (Noxl) contributes to cell invasion by regulating matrix metalloprotease- 9 production and cell migration. J Biol Chem 285: 4481-4488.

Shinohara M, Shang WH, Kubodera M, Harada S, Mitsushita J, Kato M, Miyazaki H, Sumimoto H, Kamata T (2007) Nox1 redox signaling mediates oncogenic Ras-induced disruption of stress fibers and focal adhesions by down-regulating Rho. J Biol Chem 282: 17640-17648.
Singh B, Bhat NK, Bhat HK (2012) Induction of NAD (P)H-quinone oxidoreductase 1 by antioxidants in female ACI rats is associated with decrease in oxidative DNA damage and inhibition of estrogen-induced breast cancer. Carcinogenesis 33: 156-163.

Singh R, Artaza JN, Taylor WE, Braga M, Yuan X, Gonzalez-Cadavid NF, Bhasin S (2006) Testosterone inhibits adipogenic differentiation in 3T3-L1 cells: nuclear translocation of androgen receptor complex with betacatenin and T-cell factor 4 may bypass canonical Wnt signaling to down-regulate adipogenic transcription factors. Endocrinology 47 : 141-154.

Singh R, Bhasin S, Braga M, Artaza JN, Pervin S, Taylor WE, Krishnan V, Sinha SK, Rajavashisth TB, Jasuja R (2009) Regulation of myogenic differentiation by androgens: cross talk between androgen receptor/betacatenin and follistatin/transforming growth factor-beta signaling pathways. Endocrinology 150: 1259-1268.

Singh R, Pervin S, Chaudhuri G (2002) Caspase-8-mediated BID cleavage and release of mitochondrial cytochrome $c$ during Nomega-hydroxy-Larginine-induced apoptosis in MDA-MB-468 cells. Antagonistic effects of L-ornithine. J Biol Chem 277: 37630-37636.

Sumimoto H (2008) Structure, regulation and evolution of Nox-family NADPH oxidases that produce reactive oxygen species. FEBS J 275: 3249-3277.

Toullec A, Gerald D, Despouy G, Bourachot B, Cardon M, Lefort S, Richardson M, Rigaill G, Parrini MC, Lucchesi C, Bellanger D, Stern MH, Dubois T, Sastre-Garau X, Delattre O, VincentSalomon A, Mechta-Grigoriou F (2010) Oxidative stress promotes myofibroblast differentiation and tumour spreading. EMBO Mol Med 2: 211-230.

Tsai SM, Hou MF, Wu SH, Hu BW, Yang SF, Chen WT, Chai CY, Ma H, Tsai LY (2011) Expression of manganese superoxide dismutase in patients with breast cancer. Kaohsiung. J Med Sci 27: 167-172.

Weroha SJ, Lingle WL, Hong Y, Li SA, Li JJ (2010) Specific overexpression of cyclin $\mathrm{E} \cdot \mathrm{CDK} 2$ in early preinvasive and primary breast tumors in female ACI rats induced by estrogen. Horm Cancer 1: 34-43.

White-Gilbertson SJ, Kasman L, McKillop J, Tirodkar T, Lu P, Voelkel-Johnson C (2009) Oxidative stress sensitizes bladder cancer cells to TRAIL mediated apoptosis by down-regulating anti-apoptotic proteins. J Urol 182: 1178-1185.

Yie SM, Luo B, Ye NY, Xie K, Ye SR (2006) Detection of Survivin-expressing circulating cancer cells in the peripheral blood of breast cancer patients by a RT-PCR ELISA. Clin Exp Metastasis 23: 279-289.

Youssef NS, Hewedi IH, Abd Raboh NM (2008) Immunohistochemical expression of survivin in breast carcinoma: relationship with clinicopathological parameters, proliferation and molecular classification. J Egypt Natl Canc Inst 20: 348-357.

This work is published under the standard license to publish agreement. After 12 months the work will become freely available and the license terms will switch to a Creative Commons AttributionNonCommercial-Share Alike 3.0 Unported License.

Supplementary Information accompanies this paper on British Journal of Cancer website (http://www.nature.com/bjc) 